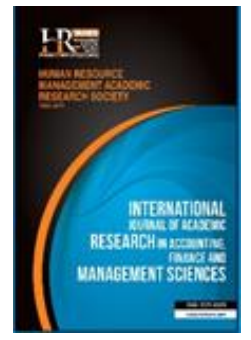

International Journal of Academic Research in Accounting, Finance and Management Sciences

Vol. 9, No.3, July 2019, pp. 221-229

E-ISSN: 2225-8329, P-ISSN: 2308-0337

(C) 2019 HRMARS

www.hrmars.com

To cite this article: Hamida, H.B.H., Scalera, F. (2019). Threshold Mean Reversion and Regime Changes of Cryptocurrencies using SETAR-MSGARCH Models, International Journal of Academic Research in Accounting, Finance and Management Sciences 9 (3): 221-229

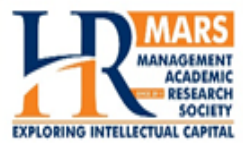

\title{
Threshold Mean Reversion and Regime Changes of Cryptocurrencies using SETAR-MSGARCH Models
}

\author{
Hayet Ben Haj Hamida ${ }^{1}$, Francesco Scalera ${ }^{2}$ \\ ${ }^{1}$ Quantitative Department University, Carthage, Institute of Higher Commercial Studies of Carthage (IHEC), Tunisia \\ University, Tunis El Manar, Faculty of Economics and Management of Tunis (FSEGT), Prospective, Strategies and \\ Sustainable Development (PS2D), Tunis 2092, Tunisia, ${ }^{1}$ E-mail: hayet.bhh@gmail.com \\ ${ }^{2}$ Department of Economics and Finance, University of Bari 'Aldo Moro', Bari, Italy, Administrative Director of the \\ Research Center CEDIMES Paris, France, ${ }^{2} E$-mail: francesco.scalera@uniba.it
}

\begin{tabular}{|c|c|c|}
\hline Abstract & \multicolumn{2}{|c|}{$\begin{array}{l}\text { In this paper we explores as to whether cryptocurrency returns exhibit asymmetric reverting patterns and } \\
\text { we test the presence of regime changes in the GARCH volatility dynamics of Bitcoin log-returns. For these } \\
\text { reason, we uses non-linear autoregressive and Markov-switching GARCH (SETAR-MSGARCH) models. We } \\
\text { finds strong evidence of regime changes in the mean and GARCH process. In addition, we conclude that bad } \\
\text { news and good news of the same size have same impacts for investors. }\end{array}$} \\
\hline Key words & \multicolumn{2}{|c|}{ Bitcoin, GARCH, Non-linear Autoregressive, Markov-Switching } \\
\hline Received: & 15 Sep 2019 & (C) The Authors 2019 \\
\hline Revised: & 24 Sep 2019 & Published by Human Resource Management Academic Research Society (www.hrmars.com) \\
\hline Published Online: & $\begin{array}{l}29 \text { Sep } 2019 \\
09 \text { Oct } 2019\end{array}$ & $\begin{array}{l}\text { This article is published under the Creative Commons Attribution (CC BY } 4.0 \text { ) license. Anyone may } \\
\text { reproduce, distribute, translate and create derivative works of this article (for both commercial and } \\
\text { non-commercial purposes), subject to full attribution to the original publication and authors. The full } \\
\text { terms of this license may be seen at: } \underline{\text { http://creativecommons.org/licences/by/4.0/legalcode }}\end{array}$ \\
\hline
\end{tabular}

\section{Introduction}

Since the global financial crisis of 2008, the international regulatory of the Basel III for bank has imposed more stringent capital requirements, and risk management systems have been developed. In fact, modelling volatility for risk management became crucial, and the international financial system has to face a new challenge evolving the introduction and development of decentralised cryptocurrencies. A cryptocurrency can be defined as "a digital asset designed to work as a medium of exchange using cryptography to secure the transactions and to control the creation of additional units of the currency" (Victor, 2017). Nakamoto (2008) designed the first decentralized cryptocurrency, Bitcoin, based on block chain technology.

Bitcoin has received much attention in the media and by investors, given its innovative feature, simplicity, transparency and its increasing popularity. Bitcoin and its derivatives use decentralized control as opposed to centralized electronic money/centralized banking systems. The decentralized control is related to the use of bitcoin's blockchain transaction database in the role of a distributed ledger. Nam, Pyun, and Arize (2002) indicated that stock market overreaction has been associated for a significant period with mean reversion of stock market price. Indeed, the overreaction of investors is based to new events and it can be determined from the assumption that a stock'price will tend to move to the average price overtime (Corbet and Katsiampa, 2018; Ahmed et al., 2018). The sharp appreciation in the price of cryptocurrency has been accurate on the presence of a substantial pricing bubble (Corbet et al., 2018a). 
Furthermore, Bitcoin is used for speculative purpose (Cheah and Fry, 2015; Corbet et al., 2018a; Hafner, 2018); it provide diversification benefits (Corbet et al., 2018b) and it is anonymity and reducing in transaction (Kim, 2017; Ahmed et al., 2016).

However, the disruption caused in the monetary market poses challenges and opportunities to policy makers, economists and investors. In addition, cryptocurrencies are volatile and it is essential to estimate appropriate risk. That it is used to calculate capital requirement, hedging and pricing derivatives. Furthermore, it is essential to study the risk related to an investment in Bitcoin. In fact, the determination of the risk managers or investor is based on adequate and essential tool. The standard GARCH models are the most used to modelling the volatility of Bitcoin. However this specification doesn't take account the presence of structural breaks that can biased the results. To display this problem, Ardia, Bluteau, and Rüede (2018b) propose to use the Markov-Switching GARCH models, whose parameters can change over time according to a discrete latent variable.

However, the structural break for modelling the returns of Bitcoin can be present on mean of this not only on variance and volatility. In this sense, we propose to test the nonlinear adjustment of Bitcoin in mean and in variance, by the way of the SETAR-MSGARCH model.

\section{Literature review}

For the literature revue, the volatility dynamic of Bitcoin returns, the estimation of Value at Risk (VaR) are performed by General Autoregressive Conditional Heteroskedasticity (GARCH) specification. Indeed, Dyhrberg (2016) has using the asymmetric GARCH model and showed that bitcoin may be useful in risk management and ideal for risk averse investors in anticipation of negative shocks to the market.

However, Bouri, Azzi, and Dyhrberg (2016) investigate the relationship between price returns and volatility changes of Bitcoin market using a daily database. The results of their study, for the entire period provide no evidence of an asymmetric return-volatility relation, using the asymmetric GARCH models, in the Bitcoin market. They show a significant inverse relation between past shocks and volatility before the crash and no significant relation after. Chu et al. (2017) provide twelve GARCH-type modelling for seven most popular cryptocurrencies: Bitcoin, Dash, Dogecoin, Litecoin, Maidsafecoin, Monero and Ripple.

They showed that GARCH models are the best fitting models, forecasts and acceptability of value at risk estimates. However, Caporale and Zekokh (2019) conclude that using standard GARCH models may yield incorrect VaR over more than $1000 \mathrm{GARCH}$ models are fitted to select the best model or set of models for modelling volatility for four cryptocurrencies (i.e. Bitcoin, Ethereum, Ripple and Litecoin).

Furthermore, many research have proved a strong evidence of regime changes in the GARCH process and show that Markov-switching GARCH (MSGARCH) models outperform single-regime specifications when predicting the VaR (Ardia et al., 2018a; Ardia et al., 2018b). In fact, MSGARCH model take account of structural breaks, and whose parameters can change over time according to a discrete latent (i.e., unobservable) variable.

Corbet and Katsiampa (2018) showed the existence of asymmetric reverting behaviour in the Bitcoin price returns using ANAR models (non-linear autoregressive), and ANAR-EGARCH models. Specifically, they use minutely, hourly, daily and weekly Bitcoin returns between June 2010 and February 2018. In addition, the examination of mean reversion dynamic in Bitcoin is essential for investors that exhibit asymmetric reaction to news.

\section{Methodology of research}

We focus on asymmetric mean reversion of short- term stock return following the approach used by Nam, Kim, and Arize (2006). We suppose that the dynamic process of a stock return evolves through the following nonlinear autoregressive process:

$$
\begin{array}{ll}
r_{t}=\mu+\phi^{-} r_{t-1}+\varepsilon_{t} & \text { if } r_{t-1}<0 \\
r_{t}=\mu+\phi^{+} r_{t-1}+\varepsilon_{t} & \text { if } r_{t-1} \geq 0
\end{array}
$$

Where $\left|\phi^{-}\right|<1$ and $\left|\phi^{+}\right|<1$ holds for the stationarity condition of $r_{t}$. Return correlation is measured by $\phi^{-}$when $r_{t}<0$, while it is measured by $\phi^{+}$when $r_{t} \geq 0$. The asymmetry property 
considered in this study implies $\phi^{+}>\phi^{-}$; i.e., serial correlation under a prior negative return is less than serial correlation under a prior positive return. $\phi^{+}$and $\phi^{-}$measure the reverting speed of $r_{t}$ under a positive and negative returns respectively.

The condition $\phi^{+}>\phi^{-}$has two implications. First, a negative return reverts on average more quickly than does the same magnitude of a positive return. Second, $\phi^{+}>\phi^{-}$measures the relative reverting magnitude of a positive return. This condition implies that the reverting magnitude of negative returns is greater than the reverting magnitude of positive returns. Therefore, the condition $\phi^{+}>\phi^{-}$ implies that a negative return reverts more quickly, with a greater reverting magnitude, to a positive return than the same-size positive return reverts to a negative return. The asymmetry property implies that a negative return is, on average, more likely to revert, with a greater reverting magnitude, to positive returns than are positive returns to revert to negative returns. To specify the asymmetric reverting dynamic, we use a univariate first order asymmetric nonlinear autoregressive model (hereafter ANAR(1)) for the return series $r_{t}$. For the daily return series $r_{t}$, Model 1 is specified as follows:

Model 1:

$r_{t}=\mu+\left[\phi_{1}+\rho_{1} D_{1}\left(r_{t-1}<0\right)\right] * r_{t-1}+\varepsilon_{t}$

Where $D_{1}$ is an indicator function specified for a dummy variable, taking a value of 1 if $r_{t-1}<0$ and 0 otherwise. Return serial correlation is measured by $\phi_{1}+\rho_{1} D_{1}$. To confirm the asymmetric reverting pattern, even with two or three consecutive price declines, the following two ANAR (1) models, Model 2 and Model 3 , are specified:

Model 2:

$r_{t}=\mu+\left[\phi_{1}+\rho_{1} D_{2}\left(r_{t-1}<0, r_{t-2}<0\right)\right] * r_{t-1}+\varepsilon_{t}$

Model 3:

$r_{t}=\mu+\left[\phi_{1}+\rho_{1} D_{3}\left(r_{t-1}<0, r_{t-2}<0, r_{t-3}<0\right)\right] * r_{t-1}+\varepsilon_{t}$

Where $D_{2}$ is an indicator function specified for a dummy variable, taking a value of 1 if $r_{t-1}<0$ and $r_{t-2}<0$ and 0 otherwise. Similarly, $D_{3}$ takes a value of 1 only if all three prior returns are negative. As in Model $1, \rho_{1}<0$ confirms that a negative return exhibits a relatively stronger asymmetry in reverting pattern.

In our research, we introduce the class of nonlinear time series models with sudden change of regime. The SETAR model proposed by Hansen (1996) is adopted which identified a sharp change between the two regimes through a lagged transition variable. Thus, the SETAR model is expressed by the following expression in the case of two regimes:

$$
r_{t}=\theta_{1}^{g} X_{t}\left(1-I\left(r_{t-d}>\tau\right)\right)+\theta_{2}^{g} X_{t}\left(1-I\left(r_{t-d}<\tau\right)\right)+\varepsilon_{t}
$$

Where $r_{t}$ is the Bitcoin returns, $X_{t}=\left(1, r_{t-1}, \ldots, r_{t-p}\right)^{\prime}$ is the vector of observations on the series $r_{t}$ until $p$ lags reproducing an autoregressive structure, $I(E)$ is an indicator function which takes value 1 when event $\mathrm{E}$ occurs and 0 otherwise. The transition variable is denoted $r_{t-d}$ with d a positive integer varying from 1 to $\mathrm{p}$. The threshold level of the structural change is identified by the coefficient $\tau$ to be estimated in addition to the vectors of the coefficients $\theta_{1}$ and $\theta_{2}$. Hansen (1996) proposes a sequential method for estimating the threshold and the coefficients of the model. In the first sequence, the estimated threshold is obtained through the minimization of the sum of squared errors which is a function of the threshold $\tau$. In the second stage, the estimated parameter $\hat{\tau}$ is put in Eq. (3) and now the whole model is estimated using appropriate methods.1 In our analysis, we restrict the transition variable as $r_{t-1}$. Error terms $\varepsilon_{t}$ are

\footnotetext{
${ }^{1}$ For more details, see Ben Salem and Perraudin (2001).
} 
assumed to be Gaussian white noises with zero mean and variance $\sigma^{2}$. The last hypothesis is very strong when studying the dynamic adjustment of Bitcoin returns. Indeed to capture heteroscedasticity of return dynamics, we utilise Markov-Switching GARCH. Let $y_{t} \in \mathbb{R}$ be the percentage log-returns of the financial asset at time t. To simplify the exposition, we assume that the log-returns have a zero mean and are not autocorrelated. The general Markov-switching GARCH specification can be expressed as:

$$
y_{t} \mid\left(S_{t}=k, I_{t-1}\right)^{\sim} F\left(0, h_{k, t}, \theta_{k}\right)
$$

Where $F\left(0, h_{k, t}, \theta_{k}\right)$ is a continuous distribution with zero mean, time-varying variance $h_{k, t}$, and additional shape parameters contained in vector $\theta_{k}$. The integer-valued stochastic variable $S_{t}$ defined on the discrete space $\{1, \ldots, k\}$ is assumed to evolve according to an unobserved first-order ergodic homogeneous Markov chain with transition probability matrix $P=\left\{p_{i, j}\right\}_{i, j=1}^{k}$ with $p_{i, j}=P\left[S_{t}=j \mid S_{t-1}=i\right]$, with $I_{t-1}$ being the information set available at time t-1. Following Haas, Mittnik, and Paolella 10.1093/jjfinec/nbh020 (2004), the conditional variance of $y_{t}$ is assumed to follow a GARCH-type model. More precisely, conditional on regime $S_{t}=k, h_{k, t}$ is specified as a function of past returns and the additional regime-dependent vector of parameters $\theta_{k}: h_{k, t} \equiv \omega\left(y_{t-1}, h_{k, t-1}, \theta_{k}\right)$

Where $h($.$) is a I_{t-1}$ measurable function which defines the filter for the conditional variance and also ensures its positiveness. By contrast, varieties of GARCH specifications are considered in the Table 1.

Table 1. varieties of GARCH specifications

\begin{tabular}{|c|c|}
\hline Model & Specification \\
\hline SGARCH (Bollerslev, 1986) & $\sigma_{t}^{2}=\omega+\sum_{i=1}^{p} \alpha_{i} \varepsilon_{t-i}^{2}+\sum_{j=1}^{q} \beta_{j} \sigma_{t-j}^{2}$ \\
\hline EGARCH (Nelson, 1991) & $\ln \left(\sigma_{t}^{2}\right)=\omega+\sum_{i=1}^{p}\left\{\alpha_{i} *\left[\frac{\left|\varepsilon_{t-i}\right|}{\sigma_{t-i}}-E\left(\frac{\left|\varepsilon_{t-i}\right|}{\sigma_{t-i}}\right)\right]+\gamma_{i} \frac{\varepsilon_{t-i}}{\sigma_{t-i}}\right\}+\sum_{j=1}^{q} \ln \left(\sigma_{t-j}^{2}\right)$ \\
\hline $\begin{array}{c}\text { GJRGARCH } \\
\text { (Glosten et al., 1993) }\end{array}$ & $\sigma_{t}^{2}=\omega+\sum_{i=1}^{p}\left[\alpha_{i}+\gamma_{i} I_{\left(\varepsilon_{t-i}>0\right)}\right] \varepsilon_{t-i}^{2}+\sum_{j=1}^{q} \beta_{j} \sigma_{t-j}^{2}$ \\
\hline TGARCH (Zakoian, 1994) & $\sigma_{t}^{2}=\omega+\sum_{i=1}^{p} \alpha_{i}\left[\left(1-\gamma_{i}\right) \varepsilon_{t-i}^{+}-\left(1-\gamma_{i}\right) \varepsilon_{t-i}^{-}\right]+\sum_{j=1}^{q} \beta_{j} \sigma_{t-j}^{2}$ \\
\hline
\end{tabular}

As for distribution mixture models, suppose that:

$$
y_{t}{ }^{\infty} D M\left(p_{1}, \ldots, p_{k} ; \mu_{1}, \ldots, \mu_{k} ; h_{1}, \ldots, h_{k}\right)
$$

Where $\mathrm{DM}$ is a mixture of densities with the following form:

$\vartheta(y)=\sum_{1}^{k} p_{i} f_{i}(y), \sum_{1}^{k} p_{i}=1, f_{i}(y)=f\left(y ; \mu_{i} ; h_{i}\right)$

Where $\left(p_{1}, \ldots, p_{k}\right)$ is the positive mixing law and $f$ denotes the density function.

\section{Empirical Results}

The series analysed are the daily closing prices of Bitcoin were taken from Coindesk Price Index and cover the period from 01 October 2013 to 12 January of 2019. Prices were transformed into log returns by taking first differences of their logarithm (Figure 1), using the following way:

$$
r_{t}=\ln \left(\frac{P_{t}}{P_{t-1}}\right)
$$


The summary statistics are reported in the Table 2 . The mean and median are $0.176 \%$ and $0.164 \%$ respectively. Data exhibit a non-normality distribution following the Jarque Berra test.

Table 2. Descriptive statistics of log returns.

\begin{tabular}{|l|c|}
\hline \multicolumn{1}{|c|}{ Statistics } & Bitcoin \\
\hline Number of obs. & 1926 \\
\hline Minimum & -0.249183 \\
\hline Q1 & -0.011887 \\
\hline Median & 0.001637 \\
\hline Mean & 0.001757 \\
\hline Q3 & 0.018526 \\
\hline Maximum & 0.279966 \\
\hline Std Dev. & 0.04364635 \\
\hline Skewness & -0.2867924 \\
\hline Kurtosis & 6.58695 \\
\hline Jarque Bera Test & $2.2 \mathrm{e}-16$ \\
\hline
\end{tabular}

Bitcoin Return

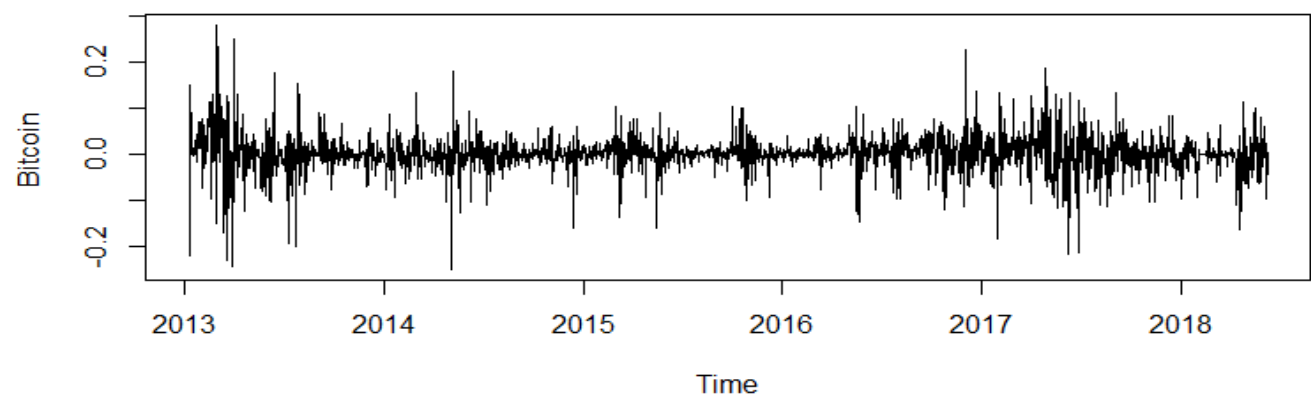

Figure 1. Log returns of Bitcoin

The Figure 2 of the histogram of our data, and they show a negative skewness of Logarithm of Bitcoin returns. Furthermore, the Figure 3 show the normal QQ plot provides a visual comparison of dataset to a standard normal distribution. Intuitively, it makes sense that the points are not align along a line since the data sets are not from the same distribution that confirm the non-normality of our distribution.

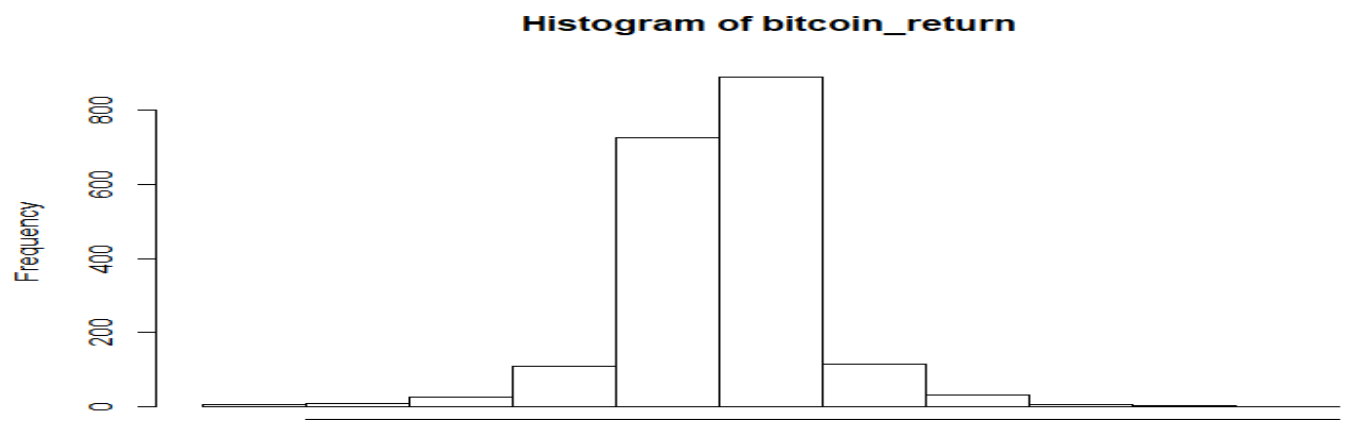

Figure 2. Histograms of log returns 


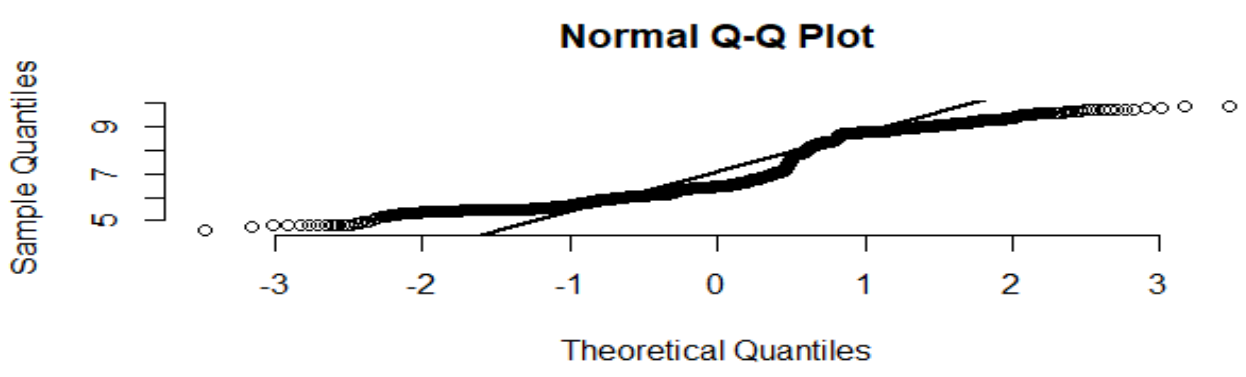

Figure 3. Quantile-Quantile plot of log returns

We first consider an in-sample analysis, where we fit the models to the full history of data. As we are interested in the volatility dynamics, we demean the series and remove autoregressive effects in the data using an SETAR(1) filter and estimate the models on the residuals.

Table 3. Nonlinear mean model of Bitcoin

\begin{tabular}{|c|c|c|c|}
\hline & Threshold & \multicolumn{2}{|c|}{$r_{t-1}$} \\
\hline \multicolumn{2}{|l|}{ Value } & \multicolumn{2}{|l|}{-0.0228} \\
\hline \multicolumn{2}{|c|}{ Proportion of points in low regime } & \multicolumn{2}{|l|}{$16.8 \%$} \\
\hline \multicolumn{2}{|c|}{ Proportion of points in High regime } & \multicolumn{2}{|l|}{$83.2 \%$} \\
\hline & Coefficients & Estimate & $\mathrm{p}$-value \\
\hline \multirow{2}{*}{$\begin{array}{l}\text { Low regime } \\
r_{t-1} \leq-0.0228\end{array}$} & const.L & 0.00104 & 0.6654 \\
\hline & phiL.1 & -0.1458 & $0.000^{* * *}$ \\
\hline \multirow{2}{*}{$\begin{array}{l}\text { High regime } \\
r_{t-1}>-0.0228\end{array}$} & const.H & 0.0019 & $0.0752^{*}$ \\
\hline & phiH.1 & 0.0672 & $0.0125^{* *}$ \\
\hline
\end{tabular}

The estimation parameters of nonlinearity of mean adjustment prove that $16.8 \%(83.2 \%)$ of observation are in the low (high) regime when the Bitcoin returns of the last period are lower (higher) than 7.16 (Table 3). This means asymmetry of Bitcoin returns is very important, that the coefficient of Bitcoin returns for the last period change of sign and its impact becomes more interested when Bitcoin returns for the last period exceed -0.0228. In another word, when Bitcoin returns for the last period exceed -0.0228 , an increase of the last variable can increase the Bitcoin returns of the period of $6.72 \%$. Following Figure 4 , the overflow of the high regime is very visualized, and that the majority of the points (data) are in the high regime. This proves that the major of Bitcoin returns exceed -0.0228 and its impact are more pronounced.

Regime switching plot

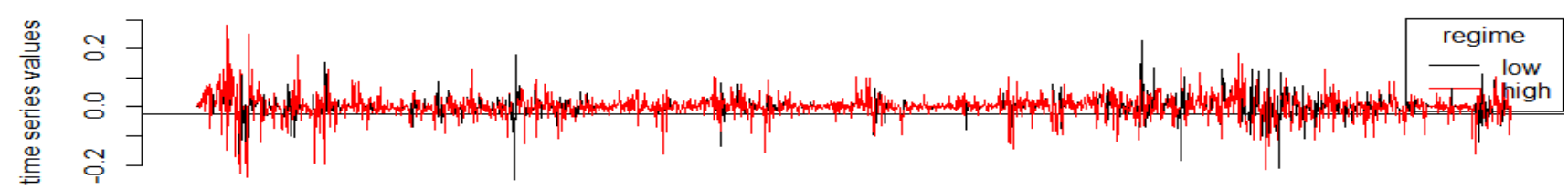

Proportion of points in low regime: $16.8 \%$
Proportion of points in High regime: $83.2 \%$

Deviance information criterion (DIC) obtained from the Bayesian estimation. In Table 4, we reports the Deviance information criterion of the 6 models (three scedastic specifications, and up to two regimes). We choose the student conditional distributions. In bold are highlighted the two-regime MSGARCH models 
that outperform their single-regime counterparts and the TGARCH (Zakoian, 1994) is more appropriate to describe the volatility of Bitcoin returns.

Table 4. Deviance information criterion

\begin{tabular}{|l|c|c|}
\hline & & DIC \\
\hline Single-regime & GARCH & $\mathbf{- 7 7 2 9 . 9 9}$ \\
\cline { 2 - 3 } & EGARCH & -7765.52 \\
\cline { 2 - 3 } & TGARCH & -7764.12 \\
\hline \multirow{3}{*}{ Two-regime } & GARCH & -7782.225 \\
\cline { 2 - 3 } & EGARCH & $\mathbf{- 7 7 4 7 . 9 5 2}$ \\
\cline { 2 - 3 } & TGARCH & $\mathbf{- 7 7 0 5 . 4 6 7}$ \\
\hline
\end{tabular}

We now consider the parameter estimates of the best in-sample model that is the SETAR-tworegime Markov-switching (SETAR-EGARCH) skewed Student-t model (Table 5).

Table 5. Parameter estimates SETAR- EGARCH (Bayesian method)

\begin{tabular}{|l|c|c|}
\hline & Regime k = 1 & Regime k =2 \\
\hline$w_{k}$ & -0.3867 & -0.5426 \\
\hline$\alpha_{1}$ & 0.1721 & 0.1910 \\
\hline$\alpha_{2}$ & 0.0793 & -0.0322 \\
\hline$\beta_{1}$ & 0.9567 & 0.9016 \\
\hline$\gamma_{k}$ & 4.3967 & 8.1496 \\
\hline P_1_1 & 0.9077 & 0.1022 \\
\hline \multicolumn{2}{|l|}{ Acceptance rate MCMC sampler : $28.2 \%$} \\
\hline
\end{tabular}

We notice that the acceptance rate of the Bayesians estimation method is very low (28.2\%), for this reason, we adopt the Maximum Likelihood method. We report parameter estimates in Table 6, where $\left(w_{k}, \alpha_{k}, \beta_{k}, \gamma_{k}\right)$ are the Exponential parameters, where $\gamma_{k}$ measures the asymmetry (i.e., leverage effect). For our analysis, the asymmetry term is positive; this implies that bad news and good news of the same size have same impacts for investors. This implies that the volatility spill over mechanism is not asymmetric ${ }^{2}$.

Table 6. Parameter estimates EGARCH (Maximum Likelihood method)

\begin{tabular}{|c|c|c|}
\hline & Regime $\mathrm{k}=1$ & Regime $\mathrm{k}=2$ \\
\hline$w_{k}$ & $-0.01311(0.000)^{* * *}$ & $-0.0353(0.0627)^{*}$ \\
\hline$\alpha_{1}$ & $0.3989(0.000) * * *$ & $-0.0016(0.3883)$ \\
\hline$\alpha_{2}$ & $0.0123(0.425)$ & $0.0589(0.07272)^{*}$ \\
\hline$\beta_{1}$ & $0.9815(0.000)^{* * *}$ & $0.9944(0.000) * * *$ \\
\hline$\gamma_{k}$ & $2.3021(0.000)^{* * *}$ & $10.6898(0.000)^{* * *}$ \\
\hline P_1_1 & $0.9784(0.000)^{* * *}$ & $0.0495(0.000)^{* * *}$ \\
\hline \multicolumn{3}{|l|}{$\begin{array}{l}\text { AIC : }-7795.1275 \\
\text { BIC : }-7728.3878\end{array}$} \\
\hline \multicolumn{3}{|l|}{$\begin{array}{l}\text { Stable probabilities : } \\
\text { State } 1: 0.6959 \\
\text { State } 2: 0.3041\end{array}$} \\
\hline
\end{tabular}

Following the

\footnotetext{
2 For extensive details you can check with the original article of Nelson (1991) EGARCH Approach.
} 
Figure 5, we can deduce that our model describe perfectly the series of Bitcoin return.
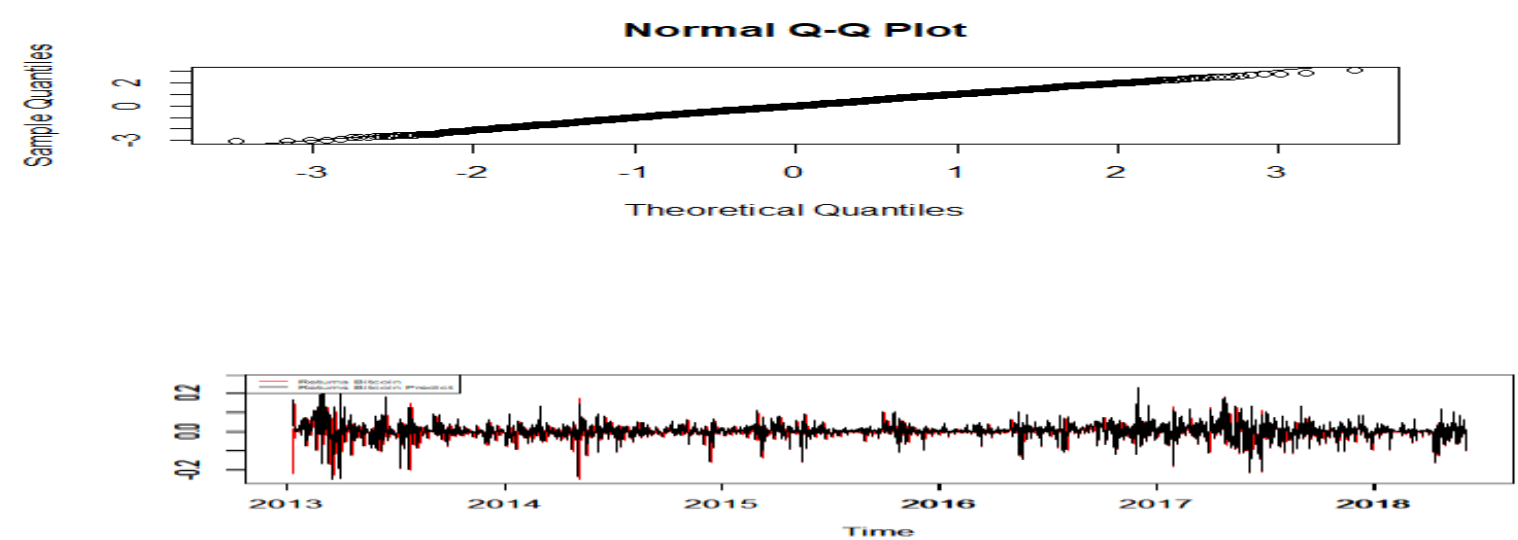

Figure 5. Quantile-Quantile plot of log returns predict

\section{Conclusions}

Given the growing interest in the Bitcoin cryptocurrency, it is of primary importance to choose reliable models to explore the asymmetric reverting behavior and to forecast the risk in such an investment. For this reason, so far, the most studies are focus on volatility dynamic and specification, we specify the nonlinear dynamic of Bitcoin returns in mean and in variance. By using specifications, which take account for regime change in mean and volatility (GARCH), namely SETAR- Markov-switching GARCH models. We show that Bitcoin daily log-returns indeed exhibit regime changes in their mean and volatility dynamics. We conclude that investors are sensitive to the bad and good financial information. Overall, our finding implies that it is very important to take account of the nonlinearity of the mean and the variance volatility of Bitcoin cryptocurrency. The results and practical advice can be summarized as follows: First, the risk manager should be modelized with Markov-Switching specification. Second, the threshold strategy of Bitcoin cryptocurrency is used and it is beneficial to show the mean reversion process.

Despite the extensive research conducted on cryptocurrencies, very few studies have examined their mean reversion property and process. We can cited Nam et al. (2002), Nam et al. (2006), and Corbet and Katsiampa (2018). The last one has used the ANAR model to specify the asymmetric reverting behaviour of the cryptocurrency price. In our study, we have extended the research of Corbet and Katsiampa (2018), and we have introduced a more general nonlinear process (SETAR model) to take account the presence of the nonlinear adjustment of cryptocurrency price. The results have showed the presence of two regime of mean reversion of cryptocurrency price. This nonlinearity can be due to the time difference between transaction and response. For this case, the knowing of the mean and/or volatility threshold is always the primary move before investing for investor and trades.

\section{References}

1. Ardia, D., Bluteau, K., Boudt, K., \& Catania, L. (2018a). Forecasting risk with Markov-switching GARCH models:A large-scale performance study. International Journal of Forecasting, 34(4), 733-747. doi: https://doi.org/10.1016/j.jijorecast.2018.05.004 
2. Ardia, D., Bluteau, K., \& Rüede, M. (2018b). Regime changes in Bitcoin GARCH volatility dynamics. Finance Research Letters. doi: https://doi.org/10.1016/j.frl.2018.08.009

3. Ahmed, U., Majid, A. H. A., \& Zin, M. L. M. (2016). HR Moderating HR: Critical link between Developmental HR Practices and work engagement in a Moderated Model. Management Review: An International Journal, 11(2), 4-22.

4. Ahmed, U., Umrani, W. A., Qureshi, M. A., \& Samad, A. (2018). Examining the links between teachers support, academic efficacy, academic resilience, and student engagement in Bahrain. International Journal of Advanced and Applied Sciences, 5(9), 39-46.

5. Salem, B. M., \& Perraudin, C. (2001). Tests de linéarité, spécification et estimation de modèles à seuil : une analyse comparée des méthodes de Tsay et de Hansen. [Linearity Tests and Threshold Model Specification and Estimation: A Comparative Analysis of the Tsay and Hansen Methods]. Economie \& prévision, 148(2), 157-176.

6. Bollerslev, T. (1986). Generalized autoregressive conditional heteroskedasticity. Journal of Econometrics, 31(3), 307-327. doi: https://doi.org/10.1016/0304-4076(86)90063-1

7. Bouri, E., Azzi, G., \& Dyhrberg, A. H. (2016). On the return-volatility relationship in the Bitcoin market around the price crash of 2013.

8. Caporale, G. M., \& Zekokh, T. (2019). Modelling volatility of cryptocurrencies using MarkovSwitching GARCH models. Research in International Business and Finance, 48, 143-155. doi: https://doi.org/10.1016/j.ribaf.2018.12.009

9. Cheah, E. T., \& Fry, J. (2015). Speculative bubbles in Bitcoin markets? An empirical investigation into the fundamental value of Bitcoin. Economics Letters, 130, 32-36. doi: https://doi.org/10.1016/j.econlet.2015.02.029

10. Chu, J., Chan, S., Nadarajah, S., \& Osterrieder, J. (2017). GARCH modelling of cryptocurrencies. Journal of Risk and Financial Management, 10(4), 17.

11. Corbet, S., \& Katsiampa, P. (2018). Asymmetric mean reversion of Bitcoin price returns. International Review of Financial Analysis. doi: https://doi.org/10.1016/j.irfa.2018.10.004

12. Corbet, S., Lucey, B., \& Yarovaya, L. (2018a). Datestamping the Bitcoin and Ethereum bubbles. Finance Research Letters, 26, 81-88. doi: https://doi.org/10.1016/j.frl.2017.12.006

13. Corbet, S., Meegan, A., Larkin, C., Lucey, B., \& Yarovaya, L. (2018b). Exploring the dynamic relationships between cryptocurrencies and other financial assets. Economics Letters, 165, 28-34. doi: https://doi.org/10.1016/j.econlet.2018.01.004

14. Dyhrberg, A. H. (2016). Bitcoin, gold and the dollar - A GARCH volatility analysis. Finance Research Letters, 16, 85-92. doi: https://doi.org/10.1016/j.frl.2015.10.008

15. GLOSTEN, L. R., JAGANNATHAN, R., \& RUNKLE, D. E. (1993). On the Relation between the Expected Value and the Volatility of the Nominal Excess Return on Stocks. The journal of finance, 48(5), 1779-1801. doi: doi:10.1111/j.1540-6261.1993.tb05128.x

16. Haas, M., Mittnik, S., \& Paolella, M. S. (2004). A New Approach to Markov-Switching GARCH Models. Journal of financial econometrics, 2(4), 493-530. doi: 10.1093/jjfinec/nbh020

17. Hafner, C. (2018). Testing for bubbles in cryptocurrencies with time-varying volatility.

18. Hansen, B. E. (1996). Inference When a Nuisance Parameter Is Not Identified Under the Null Hypothesis. Econometrica, 64(2), 413-430. doi: 10.2307/2171789

19. Kim, T. (2017). On the transaction cost of Bitcoin. Finance Research Letters, 23, 300-305.

20. Nakamoto, S. (2008). Bitcoin: A peer-to-peer electronic cash system. doi:

https://bitcoin.org/bitcoin.pdf.Workingpaper.

21. Nam, K., Kim, S. W., \& Arize, A. C. (2006). Mean reversion of short-horizon stock returns: asymmetry property. Review of Quantitative Finance and Accounting, 26(2), 137-163.

22. Nam, K., Pyun, C. S., \& Arize, A. C. (2002). Asymmetric mean-reversion and contrarian profits: ANST-GARCH approach. Journal of Empirical Finance, 9(5), 563-588. doi: https://doi.org/10.1016/S09275398(02)00011-7

23. Nelson, D. B. (1991). Conditional heteroskedasticity in asset returns: A new approach. Econometrica: Journal of the Econometric Society, 347-370.

24. Victor, A. (2017). INTRODUCING CRYPTOCURRENCY (Vol. 1). 
International Journal of Academic Research in Accounting, Finance and Management Sciences

Vol. 9 (3), pp. 221-229 @ 2019 HRMARS (www.hrmars.com)

25. Zakoian, J. M. (1994). Threshold heteroskedastic models. Journal of Economic Dynamics and Control, 18(5), 931-955. doi: https://doi.org/10.1016/0165-1889(94)90039-6 